\title{
Synthesis of Seco-Chlorinated Derivatives of Phenanthroindolizidine Precursors via Friedel-Crafts Reaction
}

\author{
Songtao Li, Li Han, Jiang Liu, Yihan Hu, Dan Zheng, Yingbo Fu and Xueshi Huang* \\ Department of Natural Products Chemistry, Pharmaceutical School, China Medical University, \\ Shenyang 110001, China \\ * Author to whom correspondence should be addressed; E-Mail: xshuang@mail.cmu.edu.cn; \\ Tel.: +00-8624-23256666-5250.
}

Received: 9 October 2010; in revised form: 14 November 2010 / Accepted: 14 November 2010 / Published: 22 November 2010

\begin{abstract}
In the course of synthesizing 3-demethyltylophorine (1) by Lewis acid catalyzed intramolecular Friedel-Crafts reaction starting from $N$-(3-hydroxy-2,6,7-trimethoxyphenanthr-9-ylmethyl)-2-chloromethylpyrrolidine, two chlorinated phenanthrene derivatives $\quad N$-(4,10-dichloro-3-hydroxy-2,6,7-trimethoxyphenanthr-9-ylmethyl)-2chloromethylpyrrolidine (4) and $N$-(4-chloro-3-hydroxy-2,6,7-trimethoxyphenanthr-9ylmethyl)-2-chloromethylpyrrolidine (5) were obtained. The structures of these compounds were determined by spectroscopic analysis.
\end{abstract}

Keywords: phenanthroindolizidine; antitumor; Friedel-Crafts reaction

\section{Introduction}

Phenanthroindolizidine alkaloids, which were mainly isolated from Asclepiadaceae family [1], have attracted an intense attention because of their notable biological properties [2], especially the antitumor activity [3]. Many isolations, synthetic methodologies and biological activity studies [2,4] of this class of natural products have been reported since the first isolation of tylophorine in 1935 [5]. Despite of the potential biological activities, phenanthroindolizidine alkaloids have not yet been developed as clinical therapeutic drugs due to their serious central nervous system (CNS) side effects [1]. Inspired by this result, we attempt to synthesize a 3-demethyltylophorine (1, Scheme 1) and a series of derivatives based upon the functional 3-hydroxyl group on the phenanthrene ring, aimed at studying the impacts of the alternative polarities of these analogues on the antitumor activity and the CNS toxicity. 
Scheme 1. Synthesis of 4 and 5.

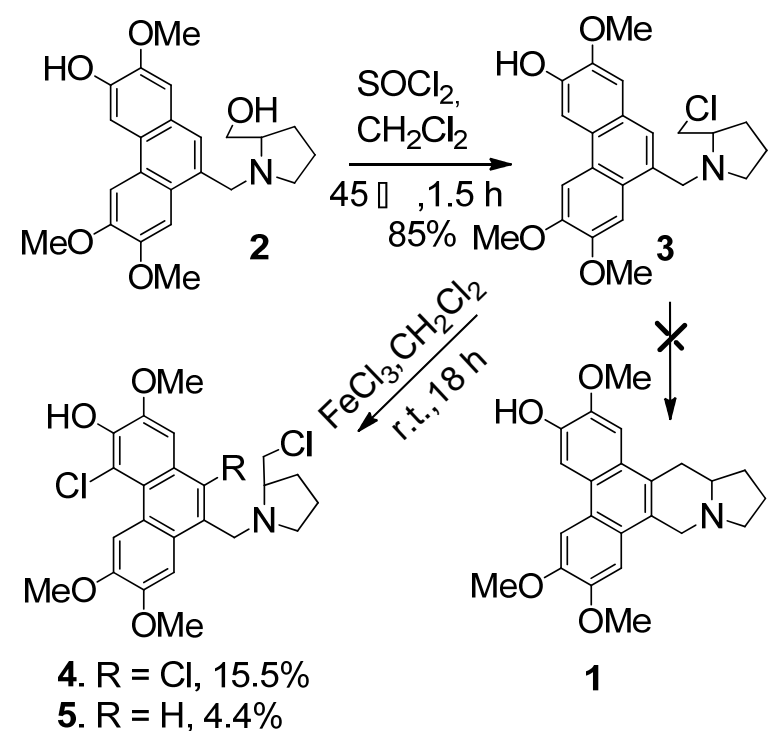

The previous synthetic routes of phenanthroindolizidine alkaloids focused mainly on two directions: one was to finish the indolizidine unit followed by closing the phenanthrene ring [6-9]; the other involved the cyclization of phenanthrene firstly, then the synthesis of indolizidine ring system in the ultimate stage [10-13]. For the latter strategy, the typical method was via an amino (or amido) acid [14] to construct the indolizidine nucleus, and the commonly used building block was proline or its analogues [11]. In 1961, Govindachari and co-workers [15] reported that $N$-(2,3,6,7-tetramethoxyphenanthrylmethyl)prolinol unsuccessfully linked to the phenanthrene ring under a variety of conditions attempted; In 1969, Chauncy et al. found that (-)- $N$-phenanthr-9-ylmethyl-L-prolyl bromide was failed to give the ring closure product by the Friedel-Crafts alkylation reaction, but polyphosphoric acid catalyzed acylation of the hydrochloride of (-)- $N$-phenanthr-9-ylmethyl-L-proline was successful [16]. However, the unstable ketone intermediate and low yield limited its application. In 1983, Rapoport et al. [11] attempted to catalyze the intramolecular Friedel-Crafts acylation of proline by Lewis acid, but it failed to give the ketone. In 2004, Banwell and Sydnes [17] reported that the seco-chlorinated derivatives of phenanthroindolizidine did not end up with the target ring closure products either. None of them, however, gave the detailed information of the reaction and the final products. As a part of our current work, we previously synthesized two intermediates: $N$-(3-hydroxy2,6,7-trimethoxyphenanthr-9-ylmethyl)-L-prolinol (2) and $N$-(3-hydroxy-2,6,7-trimethoxyphenanthr-9ylmethyl)-2-chloromethyl pyrrolidine (3). On treatment with concentrated $\mathrm{H}_{2} \mathrm{SO}_{4} / \mathrm{HOAc}, 2$ gave its acetate and hydrogen sulfate ester instead of the cyclized compound 1 [18]. Intramolecular FriedelCrafts reaction of $\mathbf{3}$ catalyzed by chlorinated Lewis acids did not give $\mathbf{1}$ either (Scheme 1). In this paper, we reported the details of the products obtained from the intramolecular Friedel-Crafts reaction of 3. 


\section{Results and Discussion}

Catalyzed by anhydrous $\mathrm{AlCl}_{3}$ in anhydrous $\mathrm{CH}_{2} \mathrm{Cl}_{2}$ at room temperature, 3 afforded a demethylated analogue 3a (20\%). The ${ }^{1} \mathrm{H}$ NMR spectrum of 3a was close similar to that of $\mathbf{3}$ except for the absence of signal due to a methoxyl group. Furthermore, the chemical shifts of aromatic protons at C-4 and C-5 positions $(\Delta \delta: 7.77-7.76=0.01 \mathrm{ppm})$ in 3a were more approximate than those in $3(\Delta \delta: 7.86-7.82=0.04 \mathrm{ppm})$ [18]. Thus the structure of 3a was established as 6-demethyl analogue of 3. On treatment with anhydrous $\mathrm{FeCl}_{3}$ in anhydrous $\mathrm{CH}_{2} \mathrm{Cl}_{2}$ at room temperature, 3 furnished two chlorinated phenanthrene analogues $4(15.5 \%)$ and $5(4.4 \%)$. Reaction in anhydrous $\mathrm{CS}_{2}$, in the presence of anhydrous $\mathrm{FeCl}_{3}, 3$ also gave 4 (21.5\%) as the main product (Scheme 1). In order to determine the structures of $\mathbf{4}$ and 5, 1D NMR, 2D NMR and ESI mass spectra were determined for 4. ESIMS indicated quasi-molecular ion peak at $m / z 484[\mathrm{M}+\mathrm{H}]^{+}$. The approximate relative intensities of the three peaks at $m / \mathrm{z} 484[\mathrm{M}+\mathrm{H}]^{+}, 486[(\mathrm{M}+2)+\mathrm{H}]^{+}$and $488[(\mathrm{M}+4)+\mathrm{H}]^{+}$in a ratio of 3:3:1 in the ESI mass spectrum of 4 indicated the presence of three chlorine atoms in this structure and 4 was dichloro-substituted analogue of 3. The molecular formula of $\mathrm{C}_{23} \mathrm{H}_{24} \mathrm{Cl}_{3} \mathrm{NO}_{4}$ was determined together with the analysis of its NMR data. There were only three aromatic proton signals at $\delta 9.20,7.89$ and 7.85 in the ${ }^{1} \mathrm{H}$ NMR spectrum, which indicated another two chlorine atoms were located at phenanthrene ring. NOE effect observed in a NOESY spectrum between the proton at $\delta=9.20 \mathrm{ppm}$ and methoxyl group at $\delta=4.08$ ppm suggested that one chlorine atom could be located at C-4 position (Figure 1), together with lower field chemical shift of the proton at C-5 position caused by perieffect of the chlorine substituent at C-4 position. Another chloride group has to be located at C-10 position according to the NOE effects between the proton at $\delta=7.89 \mathrm{ppm}$ and methoxyl group at $\delta=4.05 \mathrm{ppm}$ and between the proton at $\delta=7.85 \mathrm{ppm}$ and methoxyl group at $\delta=4.08 \mathrm{ppm}$. These evidences were supported by HMBC correlations as shown in Figure 1. All NMR data of $\mathbf{4}$ were assigned by COSY, NOESY, HMQC, and HMBC experiments (Figure 1).

Figure 1. Relevant COSY, NOE and HMBC correlations of 4.

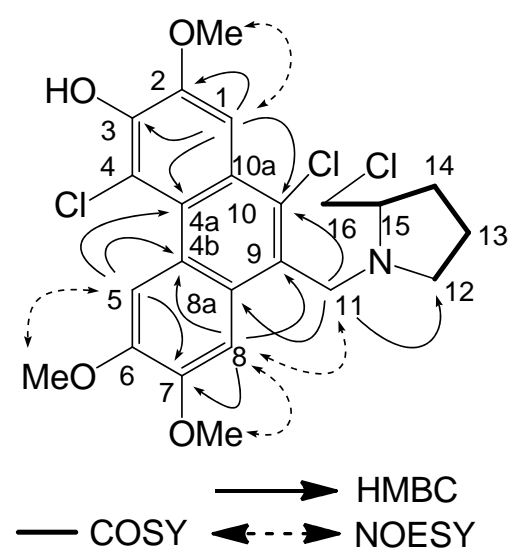

The approximate relative intensities of the three peaks at $m / z 450[\mathrm{M}+\mathrm{H}]^{+}, 452[(\mathrm{M}+2)+\mathrm{H}]^{+}$and $454[(\mathrm{M}+4)+\mathrm{H}]^{+}$in a ratio of 9:6:1 in the ESI mass spectrum of 5 indicated the presence of two $\mathrm{Cl}$ atoms in this structure. Following the same logic used for compound $\mathbf{4}$, the chlorine atom was determined to be located at C-4 position from lower field chemical shift at $\delta=9.36 \mathrm{ppm}$ for aromatic 
proton. The source of chlorination may come from the dissociative chlorine mixed in $\mathrm{FeCl}_{3}$. This result indicated that the electrophilicity of chlorine was stronger than primary chloroalkane in the electrophilic aromatic substitution reaction. C-4 and C-10 positions of compound 3 have higher chlorinated reactivities than other positions on the phenanthrene ring.

\section{Experimental}

\subsection{General}

All chemicals were commercially available and used without further purification unless otherwise stated. Anhydrous $\mathrm{CH}_{2} \mathrm{Cl}_{2}$ was dried over $\mathrm{P}_{2} \mathrm{O}_{5}$ and freshly distilled before use. Anhydrous $\mathrm{CS}_{2}$ was dried over anhydrous $\mathrm{CaCl}_{2}$ and freshly distilled before use. Melting points of the synthesized compounds were determined on a Digital Melting Point Appatatus XT4A and are uncorrected. 1D NMR spectra were recorded on Bruker ARX-300 spectrometer; 2D NMR spectra, on Bruker AV-600 spectrometer. ESIMS were recorded by Finnigan LCQ mass spectrometer. Column chromatography was carried out on silica gel (200-300 mesh, Qingdao Marine Chemical Ltd., Qingdao, China). Thinlayer chromatography (TLC) was performed on TLC silica gel 60 F254 plates (0.5 mm, Merck).

\subsection{Synthesis of N-(3,6-dihydroxy-2,7-dimethoxyphenanthr-9-ylmethyl)-2-chloromethylpyrrolidine (3a)}

To a suspension of anhydrous $\mathrm{AlCl}_{3}(150 \mathrm{mg}, 1.12 \mathrm{mmol})$ in anhydrous $\mathrm{CH}_{2} \mathrm{Cl}_{2}(15 \mathrm{~mL})$ was added a solution of $3(50 \mathrm{mg}, 0.12 \mathrm{mmol})$ in anhydrous $\mathrm{CH}_{2} \mathrm{Cl}_{2}(15 \mathrm{~mL})$ under nitrogen. The reaction mixture was stirred for $24 \mathrm{~h}$ at room temperature and monitored by TLC. After the starting material was consumed, saturated $\mathrm{Na}_{2} \mathrm{CO}_{3}$ solution $(20 \mathrm{~mL})$ was added to the reaction system with vigorous stirring. The $\mathrm{CH}_{2} \mathrm{Cl}_{2}$ layer was separated and the aqueous layer was extracted with $\mathrm{CH}_{2} \mathrm{Cl}_{2}(20 \mathrm{~mL} \times 2)$. The combined organic extracts were washed with brine, dried over anhydrous sodium sulfate, filtered, and concentrated. The crude product was purified by column chromatography on silica gel $\left(\mathrm{CH}_{2} \mathrm{Cl}_{2} / \mathrm{P}\right.$.E./ethyl acetate, 10:5:1 v/v) to afford 3a (9.6 mg, 20\%) as a pale brown solid; m.p. 206-208 ${ }^{\circ} \mathrm{C}$; ${ }^{1} \mathrm{H}$ NMR $\left(300 \mathrm{MHz}, \mathrm{CDCl}_{3}\right) \delta: 1.62\left(\mathrm{~m}, 1 \mathrm{H}, 0.5 \times \mathrm{CH}_{2}\right), 1.75\left(\mathrm{~m}, 2 \mathrm{H}\right.$ overlapped, $\left.\mathrm{CH}_{2}\right), 2.12(\mathrm{~m}, 1 \mathrm{H}$, $\left.0.5 \times \mathrm{CH}_{2}\right), 2.20\left(\mathrm{~m}, 1 \mathrm{H}, 0.5 \times \mathrm{CH}_{2} \mathrm{~N}\right), 2.26\left(\mathrm{~m}, 1 \mathrm{H}, 0.5 \times \mathrm{CH}_{2} \mathrm{Cl}\right), 2.90\left(\mathrm{~m}, 1 \mathrm{H}, 0.5 \times \mathrm{CH}_{2} \mathrm{~N}\right), 3.20(\mathrm{~m}$, $\left.1 \mathrm{H}, 0.5 \times \mathrm{CH}_{2} \mathrm{Cl}\right), 3.80\left(\mathrm{~d}, 1 \mathrm{H}, J=12.9 \mathrm{~Hz}, 0.5 \times \mathrm{ArCH}_{2} \mathrm{~N}\right), 3.93\left(\mathrm{~d}, 1 \mathrm{H}, J=12.9 \mathrm{~Hz}, 0.5 \times \mathrm{ArCH}_{2} \mathrm{~N}\right)$, $4.02\left(\mathrm{~s}, 6 \mathrm{H}, 2 \times \mathrm{OCH}_{3}\right), 4.05(\mathrm{~m}, 1 \mathrm{H}, \mathrm{CHN}), 7.17$ (s, 1H, Ar-H), $7.46(\mathrm{~s}, 1 \mathrm{H}, \mathrm{Ar}-\mathrm{H}), 7.76(\mathrm{~s}, 1 \mathrm{H}, \mathrm{Ar}-\mathrm{H})$, 7.77 (s, 1H, Ar-H), 7.93 (s, 1H, Ar-H).

\subsection{Synthesis of $N$-(4,10-dichloro-3-hydroxy-2,6,7-trimethoxyphenanthr-9-ylmethyl)-2-chloro} methylpyrrolidine (4) and N-(4-chloro-3-hydroxy-2,6,7-trimethoxyphenanthr-9-ylmethyl)-2chloromethylpyrrolidine (5).

To a solution of $3(100 \mathrm{mg}, 0.24 \mathrm{mmol})$ in anhydrous $\mathrm{CH}_{2} \mathrm{Cl}_{2}(30 \mathrm{~mL})$ was added anhydrous $\mathrm{FeCl}_{3}$ $(0.4 \mathrm{~g}, 2.46 \mathrm{mmol})$ under nitrogen. The reaction mixture was stirred for $18 \mathrm{~h}$ at room temperature and monitored by TLC. After the starting material was consumed, $10 \%$ ammonia water $(30 \mathrm{~mL})$ was added to the reaction system with vigorous stirring. The $\mathrm{CH}_{2} \mathrm{Cl}_{2}$ layer was separated and the aqueous layer was extracted with $\mathrm{CH}_{2} \mathrm{Cl}_{2}(30 \mathrm{~mL} \times 2)$. The combined organic extracts were washed with brine, dried over anhydrous sodium sulfate, filtered, and concentrated. The crude product was purified by column 
chromatography on silica gel (hexane/ethyl acetate, $3: 1 \mathrm{v} / \mathrm{v})$ to afford $4(18 \mathrm{mg}, 15.5 \%)$ as a white solid; m.p. $189-191{ }^{\circ} \mathrm{C} ;{ }^{1} \mathrm{H}$ NMR $\left(300 \mathrm{MHz}, \mathrm{CDCl}_{3}\right) \delta: 1.54\left(\mathrm{~m}, 1 \mathrm{H}, 0.5 \times 13-\mathrm{CH}_{2}\right), 1.66(\mathrm{~m}, 1 \mathrm{H}$, $\left.0.5 \times 14-\mathrm{CH}_{2}\right), 1.80\left(\mathrm{~m}, 1 \mathrm{H}, 0.5 \times 13-\mathrm{CH}_{2}\right), 2.09\left(\mathrm{~m}, 1 \mathrm{H}, 0.5 \times 14-\mathrm{CH}_{2}\right), 2.41\left(\mathrm{~m}, 1 \mathrm{H}, 0.5 \times 12-\mathrm{CH}_{2}\right)$, 2.58 (brd, $\left.J=10.0 \mathrm{~Hz}, 1 \mathrm{H}, 0.5 \times 16-\mathrm{CH}_{2} \mathrm{Cl}\right), 2.73\left(\mathrm{~m}, 1 \mathrm{H}, 0.5 \times 12-\mathrm{CH}_{2}\right), 3.10$ (brd, $J=10.0 \mathrm{~Hz}, 1 \mathrm{H}$, $\left.0.5 \times 16-\mathrm{CH}_{2} \mathrm{Cl}\right), 3.95(\mathrm{~m}, 1 \mathrm{H}, 15-\mathrm{NCH}), 4.05\left(\mathrm{~s}, 3 \mathrm{H}, 7-\mathrm{OCH}_{3}\right), 4.08\left(\mathrm{~s}, 6 \mathrm{H}, 2-\mathrm{OCH}_{3}\right.$ and $\left.6-\mathrm{OCH}_{3}\right)$, $4.20\left(\mathrm{~d}, J=12.9 \mathrm{~Hz}, 1 \mathrm{H}, 0.5 \times 11-\mathrm{CH}_{2} \mathrm{~N}\right), 4.22\left(\mathrm{~d}, J=12.9 \mathrm{~Hz}, 1 \mathrm{H}, 0.5 \times 11-\mathrm{CH}_{2} \mathrm{~N}\right), 7.85(\mathrm{~s}, 1 \mathrm{H}$, 1-ArH), 7.89 (s, 1H, 8-ArH), $9.20(\mathrm{~s}, 1 \mathrm{H}, 5-\mathrm{ArH}) .{ }^{13} \mathrm{C} \mathrm{NMR}\left(75 \mathrm{MHz}, \mathrm{CDCl}_{3}\right) \delta: 105.1(\mathrm{C}-1), 143.4$ (C-2), 145.8 (C-3), 114.6 (C-4), 122.9 (C-4a), 123.3 (C-4b), 107.5 (C-5), 148.1 (C-6), 147.3 (C-7), 106.3 (C-8), 127.7 (C-8a), 127.7 (C-9), 129.2 (C-10), 124.1 (C-10a), 57.4 (C-11), 52.4 (C-12), 24.4 (C-13), 34.5 (C-14), 56.2 (C-15), 60.8 (C-16), $3 \times \mathrm{OCH}_{3}(56.2,55.6,55.3)$ and 5 (4.7 $\left.\mathrm{mg}, 4.4 \%\right)$ as an off-white solid; m.p. 202-204 ${ }^{\circ} \mathrm{C} ;{ }^{1} \mathrm{H}$ NMR $\left(300 \mathrm{MHz}, \mathrm{CDCl}_{3}\right) \delta: 1.57\left(\mathrm{~m}, 1 \mathrm{H}, 0.5 \times \mathrm{CH}_{2}\right), 1.60(\mathrm{~m}$, $\left.1 \mathrm{H}, 0.5 \times \mathrm{CH}_{2}\right), 1.82\left(\mathrm{~m}, 1 \mathrm{H}, 0.5 \times \mathrm{CH}_{2}\right), 2.12\left(\mathrm{~m}, 1 \mathrm{H}, 0.5 \times \mathrm{CH}_{2}\right), 2.26\left(\mathrm{~m}, 1 \mathrm{H}, 0.5 \times \mathrm{CH}_{2} \mathrm{~N}\right), 2.41(\mathrm{~m}$, $\left.1 \mathrm{H}, 0.5 \times \mathrm{CH}_{2} \mathrm{Cl}\right), 2.70\left(\mathrm{~m}, 1 \mathrm{H}, 0.5 \times \mathrm{CH}_{2} \mathrm{~N}\right), 3.06\left(\mathrm{brd}, J=9.9 \mathrm{~Hz}, 1 \mathrm{H}, 0.5 \times \mathrm{CH}_{2} \mathrm{Cl}\right), 3.80(\mathrm{~d}$, $\left.J=12.9 \mathrm{~Hz}, 1 \mathrm{H}, 0.5 \times \mathrm{ArCH}_{2} \mathrm{~N}\right), 3.95\left(\mathrm{~d}, J=12.9 \mathrm{~Hz}, 1 \mathrm{H}, 0.5 \times \mathrm{ArCH}_{2} \mathrm{~N}\right), 3.97($ brs, $1 \mathrm{H}, \mathrm{NCH}), 4.05$ $\left(\mathrm{s}, 3 \mathrm{H}, \mathrm{OCH}_{3}\right), 4.08\left(\mathrm{~s}, 3 \mathrm{H}, \mathrm{OCH}_{3}\right), 4.10\left(\mathrm{~s}, 3 \mathrm{H}, \mathrm{OCH}_{3}\right), 7.14(\mathrm{~s}, 1 \mathrm{H}, \mathrm{Ar}-\mathrm{H}), 7.41(\mathrm{~s}, 1 \mathrm{H}, \mathrm{Ar}-\mathrm{H}), 7.91$ (s, 1H, Ar-H), 9.36 (s, 1H, Ar-H).

\section{Conclusions}

Intramolecular Friedel-Crafts reaction of $\mathbf{3}$ catalyzed by Lewis acids was infeasible under our conditions. Instead of giving 3-demethyltylophorine (1), two chlorinated phenanthrene derivatives 4 and 5 were obtained and their structures were confirmed by spectroscopic analysis.

\section{Acknowledgements}

This work was founded by National Natural Science Foundation of China (Grant No. 30600783) and Universities Science Research Project of Liaoning Province (No. 05L497).

\section{References and Notes}

1 Fu, Y.; Lee, S.K.; Min, H.Y.; Lee, T.; Lee J.W.; Cheng, M.S.; Kim, S.H. Synthesis and structureactivity studies of antofine analogues as potential anticancer agents. Bioorg. Med. Chem. Lett. 2007, 17, 97-100.

2. Li, Z.G.; Jin, Z.; Huang, R.Q. Isolation, total synthesis and biological activity of phenanthroindolizidine and phenanthroquinolizidine alkaloids. Synthesis 2001, 16, 2365-2378.

3. Gao, W.L.; Lam, W.; Zhong, S.B.; Kaczmarek, C.; Baker, D.C.; Cheng, Y.C. Novel mode of action of tylophorine analogs as antitumor compounds. Cancer Res. 2004, 64, 678-688.

4. Gellert, E. The indolizidine alkaloids. J. Nat. Prod. 1982, 45, 50-73.

5. Ratnagiriswaran, A.N.; Venkatachalam, K. The chemical examination of Tylophora asthmatica and isolation of the alkaloids tylophorine and tylophorinine. Indian J. Med. Res. 1935, 22, 433-441.

6. Ihara, M.; Tsuruta, M.; Fukumoto, K.; Kametani, T. A versatile and stereocontrolled synthesis of quinolizidines and indolizidines using trialkylsilyl trifluoromethanesulphonate: Total synthesis of ( \pm )-Tylophorine. J. Chem. Soc. Chem. Commun. 1985, 1159-1161. 
7. Ciufolini, M.A.; Roschangar, F. A unified strategy for the synthesis of phenanthroizidine alkaloids: Preparation of sterically congested pyridines. J. Am. Chem. Soc. 1996, 118, 12082-12089.

8. Comins, D.L.; Chen, X.H.; Morgan, L.A. Enantiopure $N$-acyldihydropyridones as synthetic intermediates: Asymmetric synthesis of (-)-Septicine and (-)-Tylophorine. J. Org. Chem. 1997, 62, 7435-7438.

9. Padwa, A.; Sheehan, S.M.; Straub, C.S. An isomünchnone-based method for the synthesis of highly substituted 2(1 H)-pyridones. J. Org. Chem. 1999, 64, 8648-8659.

10. Nordlander, J.E.; Njoroge, F.G. A short synthesis of (S)-(+)-Tylophorine. J. Org. Chem. 1987, 52, 1627-1630.

11. Buckley III, T.F.; Rapoport, H. $\alpha$-amino acids as chiral educts for asymmetric products. Chirally specific syntheses of tylophorine and cryptopleurine. J. Org. Chem. 1983, 48, 4222-4232.

12. Pearson, W.H.; Walavalkar, R. Synthesis of $( \pm)$-Tylophorine by the intramolecular cycloaddition of an azide with an $\omega$-chloroalkene. Tetrahedron 1994, 50, 12293-12304.

13. Lebrun, S.; Couture, A.; Deniau, E.; Grandclaudon, P. Total syntheses of $( \pm)$-Cryptopleurine, $( \pm)$ Antofine and ( \pm )-Deoxypergularinine. Tetrahedron 1999, 55, 2659-2670.

14. Wang, Z.W.; Wang, Q.M. Highly efficient synthesis of phenanthroquinolizidine alkaloids via Parham-type cycliacylation. Tetrahedron Lett. 2010, 51, 1377-1379.

15. Govindachari, T.R.; Lakshmikantham, M.V.; Rajadurai, S. Chemical examination of tylophora asthmatica-IV synthesis of Tylophorine. Tetrahedron 1961, 14, 284-287.

16. Chauncy, B.; Gellert, E.; Trivedi, K.N. A new synthesis of phenanthroindolizidine. Aust. J. Chem. 1969, 22, 427-429.

17. Banwell, M.G.; Sydnes, M.O. Utilization of 1-aryl-2,2-dibromocyclopropanes in synthetic approaches to phenanthroquinolizidine and phenanthroindolizidine alkaloids. Aust. J. Chem. 2004, 57, 537-548.

18. Li, S.T.; Han, L.; Sun, L.; Zheng, D.; Liu, J.; Fu, Y.B.; Huang, X.S.; Wang, Z.Y. Synthesis and antitumor activities of phenanthrene-based alkaloids. Molecules 2009, 14, 5042-5053.

Sample Availability: Samples of the compounds $\mathbf{4}$ and $\mathbf{5}$ are available from the authors.

(C) 2010 by the authors; licensee MDPI, Basel, Switzerland. This article is an open access article distributed under the terms and conditions of the Creative Commons Attribution license (http://creativecommons.org/licenses/by/3.0/). 